\title{
Unit Process Impact Assessment for Discrete Part Manufacturing: A State of the Art
}

Duflou, J.R.; Kellens, K.

\begin{abstract}
Manufacturing processes, as used for discrete part manufacturing, are responsible for a substantial part of the environmental impact of products, but are still poorly documented in terms of their environmental footprint. The lack of thorough analysis of manufacturing processes has as consequence that optimization opportunities are often not recognized and that improved machine tool design in terms of ecological footprint has only been targeted for a few common processes. To address these shortcomings, a worldwide consortium of universities and research institutes launched the $\mathrm{CO}_{2} \mathrm{PE}$ ! - Initiative (Cooperative Effort on Process Emissions in Manufacturing) [1]. This paper starts with an overview of the current shortcomings in terms of the coverage of production steps during LCA studies with existing tools. Further on, the $\mathrm{CO}_{2} \mathrm{PE}$ ! - methodology used to analyze manufacturing unit processes is summarized and some initial case studies conducted at the K.U.Leuven, which allowed to identify significant improvement potential, are presented.
\end{abstract}

\section{Introduction}

Until recently, companies investing in new machine tools primarily took functional performance and the initial purchase price into account as main selection criteria. Based on three pillars, a movement towards environmentally benign manufacturing can be determined today. Besides more stringent regulatory mandates (e.g. emission standards, worker exposure standards, banned materials...), competitive economic advantages (e.g. reduced waste treatment and disposal costs, conservation of energy, water and materials...) and proactive green behavior (e.g. corporate image, ISO 14001 Certification [3], Eco-labeling...) are also motivating 
factors to switch to environmentally being manufacturing [4]. The implementation of ecological thinking in the total life cycle of products and services in general and manufacturing processes in specific is often supported by a Life Cycle Assessment (LCA). According to the ISO 14040 [5] and 14044 [6] standards, an LCA is carried out in four distinct phases: Goal and Scope definition, Inventory Analysis (LCI), Impact Assessment (LCIA) and finally the Interpretation stage. Since the ISO standards rather reflect a general framework, the Institute for Environment and Sustainability of the European Commission recently launched the International Reference Life Cycle Data System (ILCD) Handbook which consists of a set of technical documents that provide detailed guidance on all steps required to conduct a Life Cycle Assessment [7]. Besides an accurate and transparent goal and scope definition of the intended studies, companies such as machine builders, implementing ecological thinking in their business strategies, require reliable and complete inventory data, accurate impact assessment methods as well as userfriendly LCA software and/or environmental process modeling tools. An overview of some existing alternatives for each of these needs is shown in Figure 1, and will be briefly discussed in Section 2 .

\section{State of the art}

\subsection{Inventory data}

\section{National Input-Output databases}

The economy of each country can be characterized by input output tables that specify the value of the purchases between sectors within the country and abroad, as well as the supplies to other sectors and the exports. Furthermore all other major costs and revenues can be specified. These tables have been used by several LCA experts to compile input output $(\mathrm{IO})$ databases. Environmental data per sector are divided by the total value, resulting in an environmental load per unit value. These ratios can be used to link the environmental load to all supplies through the economy, enabling us to determine an estimate for the total environmental load of the outputs of different sectors. Examples can be found for the US [8], Denmark [9], The Netherlands [10] and Japan [11]. The disadvantage of IO-databases for LCA is that processes are relatively aggregated, i.e. at the level of product groups rather than individual products. 


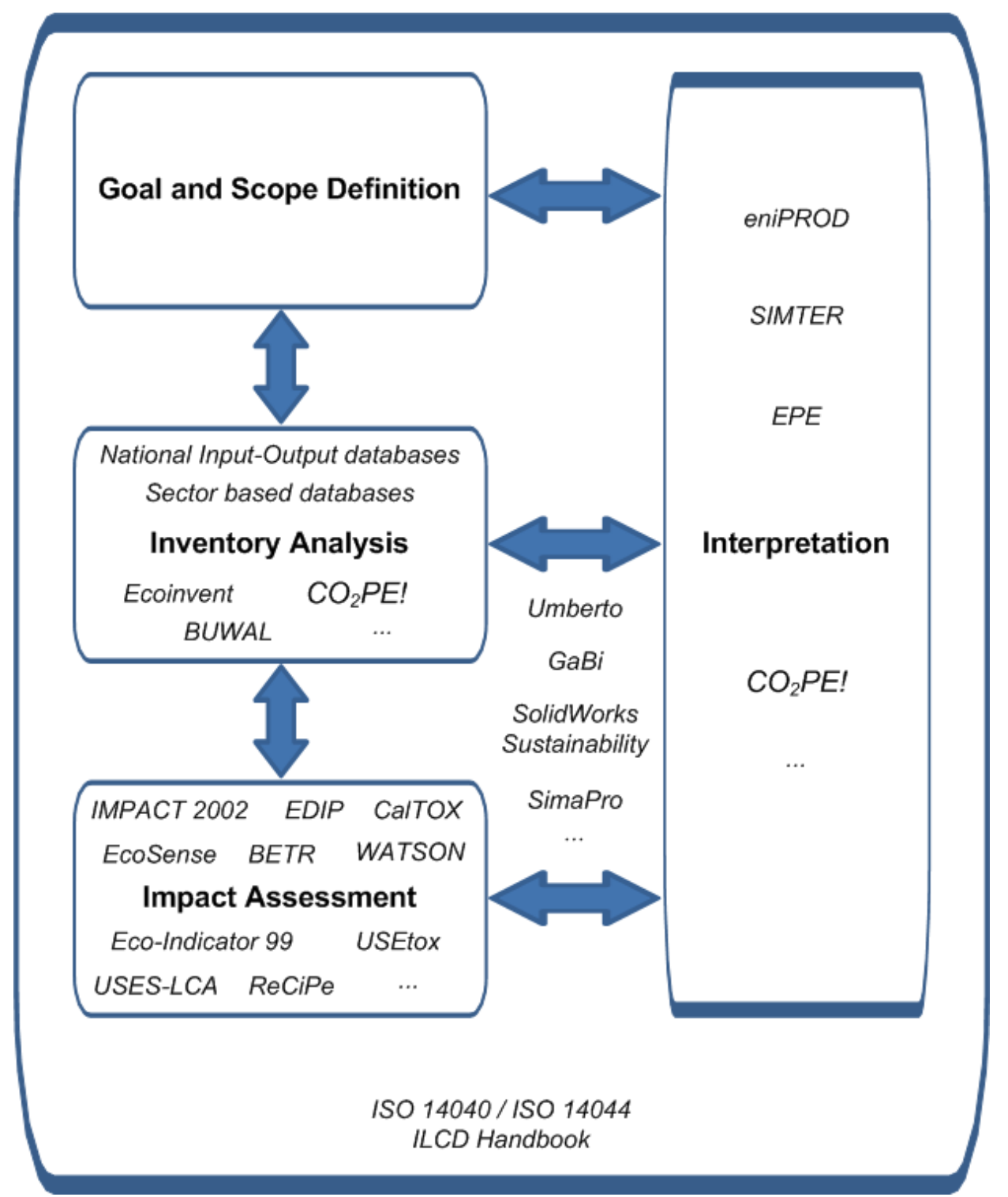

Figure 1: LCA-Framework [5, 6] 


\section{Sector based databases}

Also various industrial sectors provide LCl-data about their products. The International Iron and Steel Institute (IISI) started its worldwide life cycle inventory (LCI) study for steel products in 1996. After several updates, the version of 2010 has recently been launched [12]. Similarly, an environmental profile report for the European Aluminium Industry of 2008 is available on the website of the European Aluminium Association [13]. Eco-profiling and LCA information of the European plastics industry are provided by PlasticsEurope [14]. The BUWAL database contains packaging materials like aluminium, glass, plastics, paper and steel sheets [15]. Despite the very useful work of the respective sector organizations, their scope is often limited to the primary material production (e.g. sheets, foils...) and recycling processes.

\section{Ecoinvent database}

The Ecoinvent Centre - a Competence Centre of ETH, PSI, Empa and ART - is the world's leading supplier of consistent and transparent life cycle inventory ( $\mathrm{LCl}$ ) data of known quality and offers science-based, industrial, international life cycle assessment (LCA) and life cycle management (LCM) data and services [16]. The database update Ecoinvent data v2.2 is expected to be launched in the near future. In contrast to materials and chemicals production, manufacturing processes, as used for discrete part manufacturing, are unfortunately less well documented in terms of the overall environmental impact. On the one hand, the coverage of the wide range of available manufacturing processes is limited. On the other hand, most of the available data on manufacturing processes are incomplete: the focus is often limited to theoretical energy consumption, and data on the machine tool infrastructure or on potential emissions are rarely found [17].

\section{Public Sources}

Furthermore also some international institutions and organisations provide information on life cycle thinking-based data, tools and services. Examples can be found in the ELCD-database of the European Commission [18] and the Life Cycle Initiative launched by the United Nations Environment Programme (UNEP) and Society of Environmental Toxicology and Chemistry (SETAC) [19]. Since, the main objective of these organisations is the exchange and distribution of LCl-data to a wide audience, they mainly count on the channels mentioned above for the real LCl-data development. 


\subsection{Impact Assessment}

In a Life Cycle Assessment, the emissions and resource consumption linked to a specific product are compiled and documented in a Life Cycle Inventory (LCI). A Life Cycle Impact Assessment (LCIA) is then performed, considering human health, the natural environment, and issues related to natural resource use. Impacts considered in an LCIA include climate change, ozone depletion, acidification, eutrophication, acidification, human toxicity (cancer and non-cancer related) ecotoxicity, respiratory inorganics, ionizing radiation, photochemical ozone formation, land use, and resource depletion. The emissions and resources are assigned to each of these impact categories and converted into indicators using impact assessment models. Based on these indicators, emissions and resources consumed, as well as different product options, can be compared [5, 6, 7]. Within the wide range of available LCIA methods (e.g. EDIP [20], LIME [21], IMPACT2002 [22], USES-LCA [23], Eco-Indicator99 [24], CalTOX [25], BETR [26], WATSON [27], ReCiPe [28] ...) differences can be found in all four steps: selection of impact categories and classification, characterization, normalization (optional) and weighting (optional). Consequently, significant differences for corresponding impacts occur, which embarrass a correct interpretation. Recommendations about the use of LCIA methods can be found in the ILCD Handbook of the European Commission [7]. Furthermore, the USEtox model [29] is developed within the Life Cycle Initiative of UNEP and SETAC [19]. This model is an environmental model for the characterization of human and eco toxic impacts in LCIA and for comparative assessment and ranking of chemicals according to their inherent hazardous characteristics. The model is built on scientific consensus and harmonized elements, algorithms, parameters and property data of some LCIA methods mentioned above. Nevertheless, besides the accuracy of the used LCl-data, the generated environmental impact will be strongly influenced by the selected LCIA method. Proper documentation and transparency about the applied LCI data and LCIA methods is therefore essential for a correct interpretation and further use of the resulting environmental impacts.

\subsection{User-friendly LCA software and environmental process modeling}

GaBi [30], SimaPro [31] and Umberto [32] are three of the main LCA-software tools, which use LCI databases and LCIA methods to calculate environmental impact of 
products (and services) and can be used to compare alternative solutions. Furthermore, an increasing research trend can be observed in the implementation of ecological parameters in process design/planning tools. Among many others, some related research projects can be found in eniPROD [33], SIMTER [34], EPE [35], SolidWorks Sustainability [36] ... .

The cluster of excellence "Energy-efficient Product and Process Innovation in Production Technologies" (eniPROD) [33] of the Chemnitz University of Technology and the Fraunhofer Institute for Machine Tool and Forming Technology IWU has three main scientific objectives: 1) Key figures, models and algorithms for the description of energetic cause-effect relationships, 2) active principles, structures and technologies for the design of products and processes and 3) development, balancing and planning tools being sensitive to energy for the designing of plants.

Within the Finnish-Swedish SIMTER project [34], performed at the VTT Technical Research Centre of Finland, a discrete event simulation-based tool for manufacturing system design engineers is being developed to support optimization of sustainable manufacturing systems. The SIMTER project considers parameters grouped into three modules - 1) ergonomics, 2) levels of automation (LoA), and 3) environmental impacts - in addition to conventional production simulation parameters. The developed SIMTER tool is an interactive computer based system intended to help decision-makers use data and models to identify and solve problems and to make difficult decisions regarding sustainable manufacturing system design, especially in terms of social/human and environmental sustainability. The latter is obtained by implementing environmental metrics adapted from EPA [37, 38] and GreenSCOR [39]: direct and indirect energy consumption, direct and indirect $\mathrm{CO}_{2}$ emissions, other air emissions such as NOx and VOC's, solid and hazardous waste as well as water emissions. Since the main difficulty is getting data for environmental impact analysis, the SIMTER technique estimates energy use based on specifications provided by equipment manufacturers (e.g. manuals and vendors) and operational data (e.g. number of hours in different operation modes). Consequently, a second challenge is the accuracy or granularity of the models.

The Centre for Sustainable Manufacturing and Reuse/Recycling Technologies (SMART) at the university of Loughborough, [35] developed a framework to model the Embodied Product Energy (EPE), which is the sum of direct (theoretical and auxiliary energy) and indirect (e.g. lighting, heating...) energy consumption during the manufacturing stage of a product. This EPE enables a "Design for Energy Minimisation" approach to be adopted to reduce the energy consumption during the 
manufacturing stage of a product and provides increased transparency to the energy considerations within the LCA of products [40].

SolidWorks introduces life cycling thinking in the 3D-design software [37]. Besides an intuitive LCA tool and environmental impact dashboard, also an alternative materials selection tool and improvement reports are available. The required $\mathrm{LCl}$ data are provided by GaBi [30].

\subsection{Current shortcomings}

Manufacturing processes, as used for discrete part manufacturing, are responsible for a substantial part of the environmental impact of products, but are still poorly documented in terms of environmental footprint. Nevertheless, compared to the materials consumption, the energy and resource consumption (and related environmental impact) of the manufacturing stage of products is not negligible as often assumed in LCA-studies. From Figure 2, which shows the industrial electricity consumption for Europe (EU-27) in 2007 [41], we can conclude that the metal processing industry is responsible for about $13,7 \%$ of the total industrial electricity consumption or 158 billion kWh in Europe. For an average $3500 \mathrm{kWh}$ electricity consumption per 4-member household each year, this equals to about 45 million households. Although electricity only represents 30 percent of the total industrial energy consumption, this demonstrates already the non-negligible importance of the manufacturing stage in the general life cycle analysis of a wide range of products. Taking into account the large quantities of consumed resources, such as process gasses and lubricants, as well as the generated process emissions to both techno (e.g. waste material...) and eco sphere (e.g. air emissions...), the associated environmental impact only increases. Furthermore, a trend can be observed towards more energy intensive, unconventional processing techniques. The impact of the manufacturing sector is in consequence growing steadily [42]. In literature, Gutowski et al. [43] already reported detailed measurements at machine level for a number of machine types. They indicated that energy requirements depend on the production rate and are consequently not constant, as assumed by ecological impact-software packages, which often assume energy requirements only to be proportional to the physical amount of material processed, thus neglecting the fixed energy consumption due to unloaded motors, coolant pumps, controllers and fans, or other peripheral equipment. 


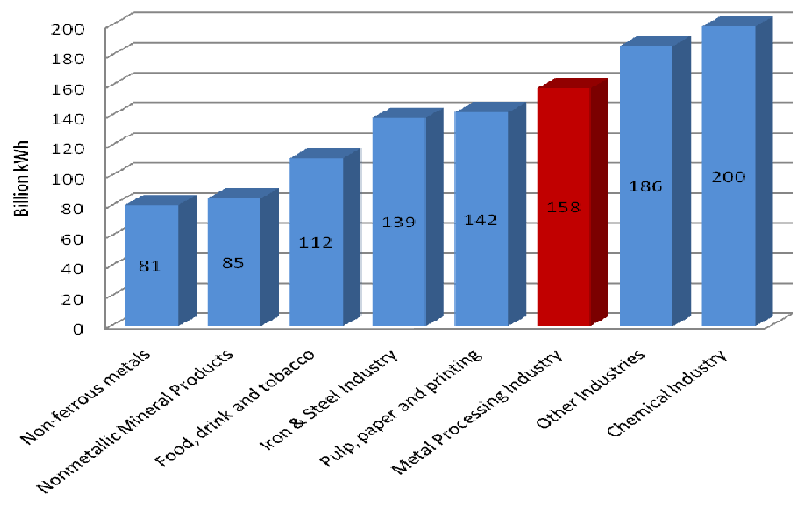

Figure 2: Industrial electricity consumption for Europe (EU-27) in 2007 [41]

To deal with the lack of thorough environmental analysis of manufacturing processes and corresponding $\mathrm{LCl}$ data, the $\mathrm{CO}_{2} \mathrm{PE}$ !-Initiative (Cooperative Effort on Process Emissions in Manufacturing), summarized in the Section 3, has been launched [1].

\section{$3 \mathrm{CO}_{2} P E$ ! - Initiative}

The $\mathrm{CO}_{2} \mathrm{PE}$ !-Initiative has the objective to coordinate international efforts aiming to document and analyze the overall environmental impact for a wide range of available and emerging manufacturing processes and to provide guidelines to improve these. In 2009, the initiative was officially recognized by CIRP as part of the Collaborative Working Group EREE [44] and IMS as Manufacturing Technology Platform (MTP) Theme [45]. Based on an extended DIN8580 taxonomy of manufacturing unit processes $[1,46]$, a worldwide data collection effort is moderated. A large number of research institutes and associated industrial partners in different continents have already joined the initiative and share the required expertise and facilities among each other. A centralized overview and coordinating effort allow to avoid undesirable redundancy in data collection efforts, and facilitate direct communication between parties with overlapping interests and expertise needs. Therefore a data-exchange platform has been launched and a methodology to systematically collect, treat and distribute data has been developed by the initiative consortium. 


\subsection{Methodology}

In this section, the goal and scope defintion as well as the in-depth approach of the process inventorisation phase of the LCA-based $\mathrm{CO}_{2} \mathrm{PE}$ ! - methodology are briefly discussed. Since the main objective of the initiative is to collect and document useful and accurate LCl data for a wide range of discrete manufacturing processes, the Impact Assessment and Interpretation steps are not included here. Nevertheless, both steps are necessary to achieve the second goal in which potential for ecological machine tool design improvements will be investigated and documented as design guidelines and/or best practices.

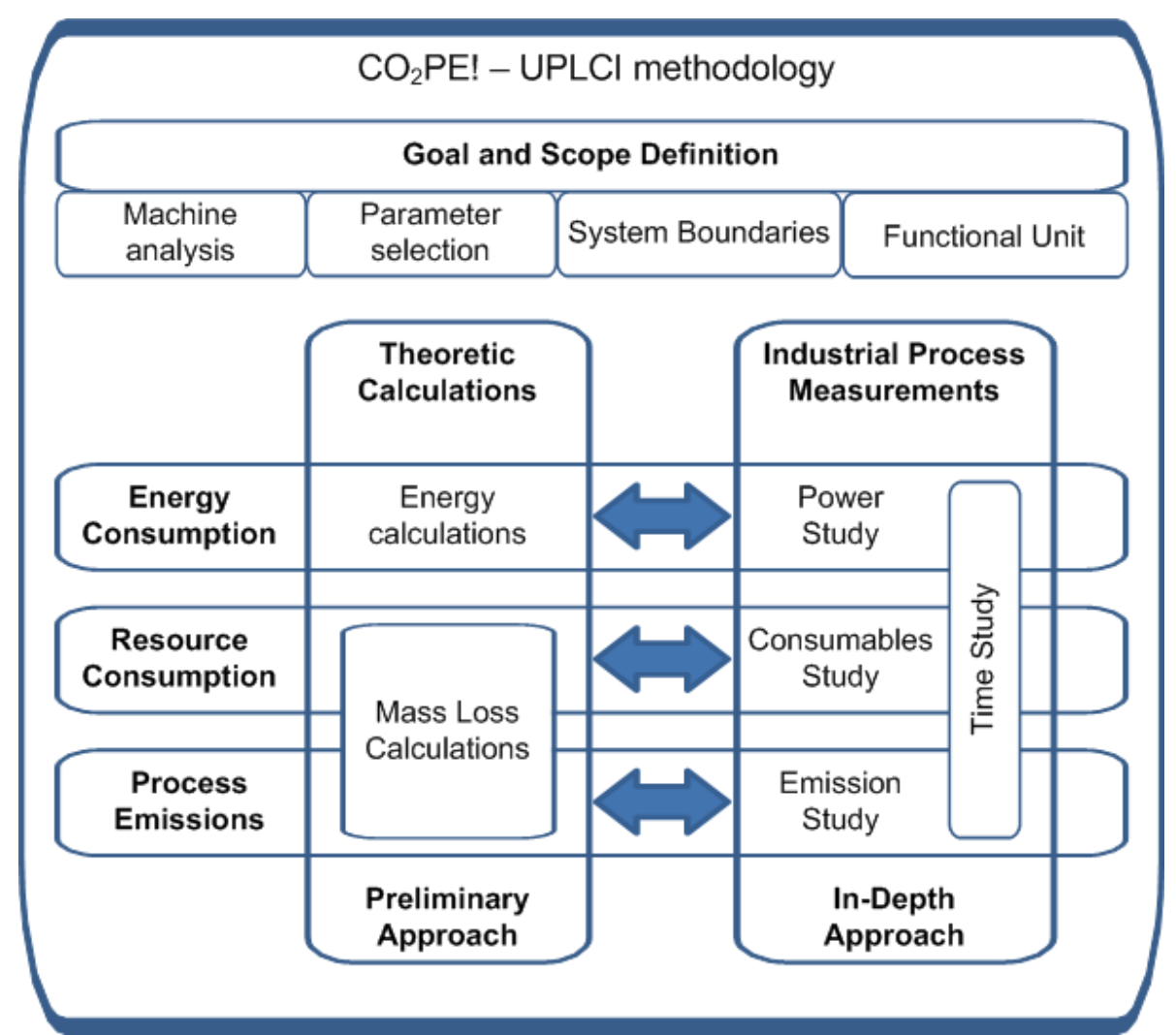

Figure 3: $\quad \mathrm{CO}_{2} P E !-U P L C l$ Methodology 


\section{Goal and Scope definition}

First the goal and scope of the study should be clearly defined and must be consistent with the intended unit process. The most important parts of the scope definition to be considered are the system boundaries and the functional unit of the intended process. Furthermore, the machine tool architecture and process parameters are investigated and all sub-processes, including subunits, are identified and located within the machine tool.

The system boundary determines which unit process is to be investigated and in how far sub processes will be analysed individually. All included in- and outputs from the techno and eco spheres must be listed. The system boundaries are set to include only the operating phase of one isolated manufacturing unit process, disregarding materials processing, production, transport, maintenance and disposal of the machine tool itself.

Besides a process dependent functional unit, which must be clearly defined both quantitatively and qualitatively, a generally applicable reference flow of 1 second of processing time for a specified load level of a unit manufacturing process for a specified material, based on a working scheme of 2000 hours/year (250 days with one shift of 8 hours) including some specified use modes is used.

Another step of the goal and scope definition is the parameter selection in which the main process parameters are ranked from largest to minor effect on the energy and resource consumption as well as the generated process emissions. The influence of the most important parameters is investigated during the following $\mathrm{LCl}$ analysis.

Finally, the machine tool architecture is investigated before an inventorisation of all selected energy and resource flows throughout the machine tool takes place. The typical use scenarios of the machine tool are considered and both energy and resource consuming units as well as emission generating sub processes of the machine tool are identified together with their functionality and location.

\section{Process inventorisation}

The in-depth approach of the process inventorisation is mainly based on industrial measurements and includes a time, power, consumables as well as emission study. Primary, a time studie is performed in order to identify the different use modes of a machine tool and their respective share in the covered time span. The identified time modes start from the machine tool start-up, over the use phase to finally switching off the machine, but are determined for periods of full machine occupancy where no idle time due to a lack of orders occurs. The energy consumption of the 
machine tool is obtained by measuring the total machine tool power consumption over a specified time period. By measuring individual power consumption patterns for all relevant active energy consuming units (ECU's) in each production mode, energy and corresponding ecological footprint optimization potential can be identified.

Parallel to the time and power measurements, the flow of consumables is measured for each process material in each production mode. Whitin this study, the consumption of process materials or inputs from the techno sphere such as compressed air, lubricants or process gasses $\left(\mathrm{N}_{2}, \mathrm{O}_{2}\right)$ are investigated. Although the raw-material flow is not relevant for a unit process study, the amount of waste created is process dependent and is therefore included as consumable.

Finally, also an emission study takes place when relevant (e.g. mass balance abnormalities, use of hazardous materials). This study includes gaseous, liquid and solid emissions as well as heat losses.

\subsection{Case Studies}

In this section, two preliminary case studies, conducted at the K.U.Leuven, are briefly presented.

\section{Laser Cutting}

The first case study was performed on a $\mathrm{CO}_{2}$-laser cutting machine tool of $5 \mathrm{~kW}$ [47]. Table 1 shows the different production modes.

Table 1: Production modes and relative time distribution of a $5 \mathrm{~kW} \mathrm{CO}_{2}$-laser cutting machine [47]

\begin{tabular}{|l|l|l|}
\hline $\mathbf{N}^{\circ}$ & Production Mode & $\%$ \\
\hline 1 & $\begin{array}{l}\text { Cutting: the laser is cutting sheets of metal or moving from one place on } \\
\text { the sheet to another to start a new contour }\end{array}$ & 84,9 \\
\hline 2 & $\begin{array}{l}\text { Table changing: the machine changes tables from the casing to the } \\
\text { loading area }\end{array}$ & 6,4 \\
\hline 3 & $\begin{array}{l}\text { ldle machine time: laser program is loading, product checking, lens } \\
\text { exchanging,... }\end{array}$ & 9,2 \\
\hline
\end{tabular}

Table 2 shows the energy, resource and emission flows and related environmental impacts during one hour of laser cutting activity [16, 24, 48]. 
Table 2: Average energy, resource and emission flows during one hour of laser cutting activity for a $5 \mathrm{~kW}$ laser power setting [47]

\begin{tabular}{|l|l|l|l|}
\hline & Production Mode & Impact (mpts) & \% Impact \\
\hline Energy & $52,2 \mathrm{kWh}$ & 1357 & 68,1 \\
\hline Process gas ( $\left.\mathrm{N}_{2}\right)$ & $13,6 \mathrm{~m}^{3}$ & 193 & 9,7 \\
\hline Produced Waste (St37-2) & $6,5 \mathrm{~kg}$ & 406 & 20,4 \\
\hline Air Emissions & $\begin{array}{l}7,3 \mathrm{mg} \mathrm{NO} 2 \\
4,9 \mathrm{mg} \mathrm{NO} \\
917 \mathrm{mg} \text { aerosols }\end{array}$ & 35 & 1,8 \\
\hline Total & & $\mathbf{1 9 9 1}$ & \\
\hline
\end{tabular}

Since most impact $(68 \%)$ is caused by the energy (electricity) consumption of the machine tool, the energy reduction potential was investigated. An alternative laser machine design was conceived, equipped with a fiber laser source with an energy efficiency of $30 \%$ and a thermostat to automatically switch to winter mode (to prevent freezing of the laser cooling circuit during off mode) when necessary. As shown in Figure 4, the achieved energy consumption reduction is respectively $29 \%$, $23 \%$ en $22 \%$ for 1,2 or 3 shifts per day, which corresponds to a total impact reduction of around $20 \%$.

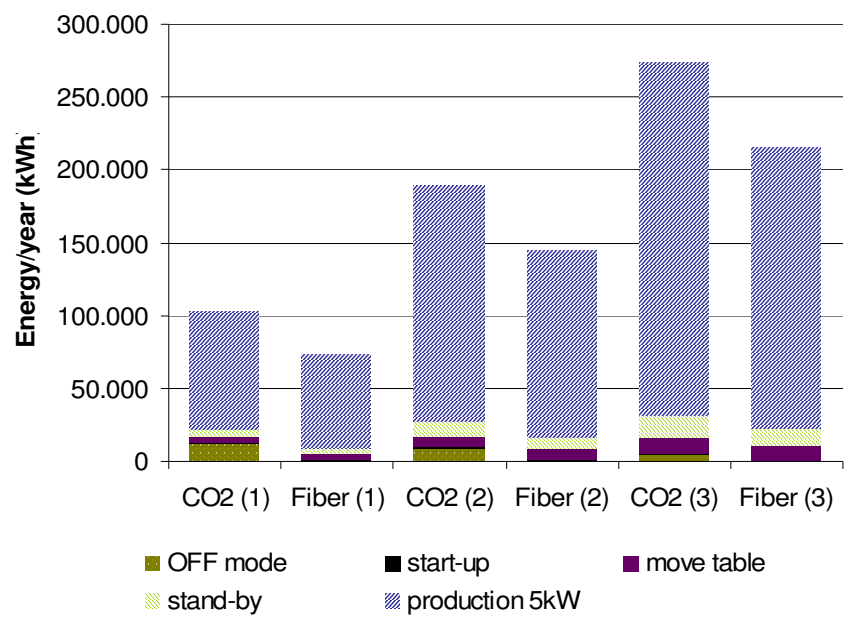

Figure 4: Comparison of yearly energy consumption for the original CO2-laser and the alternative fiber laser machine tool for three operating scenarios (1, 2 or 3 shifts) [47] 


\section{Selective Laser Melting (SLM)}

The second case study is performed on a selective laser melting (SLM) machine tool. Notably, this study includes only two products and needs more investigation before general conclusions can be made. The identified production modes are listed in Table 3.

Table 3: Production modes and relative time distribution on a selective laser melting machine tool

\begin{tabular}{|l|l|l|}
\hline $\mathbf{N}^{\circ}$ & Production Mode & $\%$ Time \\
\hline 1 & Start-up mode: an inert process atmosphere is created & 12 \\
\hline 2 & Melting: the laser is melting powder articles or moving his scan head & 68 \\
\hline 3 & Sweeping: a new layer is prepared & 5 \\
\hline 4 & $\begin{array}{l}\text { Product removing + cleaning: the products are removed and the machine } \\
\text { tool is cleaned }\end{array}$ & 15 \\
\hline
\end{tabular}

Figure 5 shows the energy distribution during productive mode for a selective laser melting process of a product with four hours of process time. Around $80 \%$ of the consumed energy is used by the (100W - YAG) laser source unit.

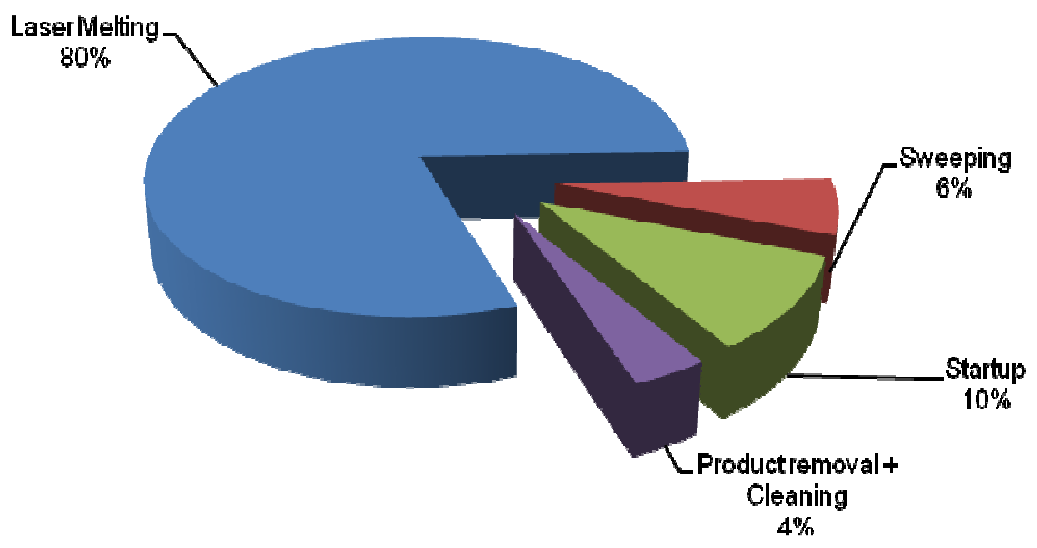

Figure 5: Energy distribution during productive mode

The energy, resource and emission flows for a product with a total production time of four hours are presented in Table 4 [16, 24]. For the emission study, data of the Laser Safety database from the Laser Zentrum Hannover e.V. were used [48]. 
Table 4: Energy, resource and emission flows for a product with a total production time of 4 hours

\begin{tabular}{|l|l|l|l|}
\hline & & Impact (mpts) & \% Impact \\
\hline Energy & $11 \mathrm{kWh}$ & 287 & 41,6 \\
\hline Process Gas $\left(\mathrm{N}_{2}\right)$ & $15,5 \mathrm{~m}^{3}$ & 308 & 44,8 \\
\hline Waste material & $0,084 \mathrm{~kg}$ & 94 & 13,6 \\
\hline Air Emissions & $\begin{array}{l}1,3 \mathrm{mg} \mathrm{NO} \mathrm{N}_{2} \\
1,3 \mathrm{mg} \mathrm{NO} \\
3,3 \mathrm{mg} \text { aerosols }\end{array}$ & $\sim 0$ & $\sim 0$ \\
\hline Total & & 689 & \\
\hline
\end{tabular}

Impact reduction opportunities could be found in all aspects. By using more efficient laser sources or powder recycling strategies, energy and waste material savings can be achieved. Another interesting impact reducing opportunity can be found in the way the inert process atmosphere is created. In the investigated machine tool, a pre-flushing flow rate of $6.5 \mathrm{~m}^{3} / \mathrm{h}$ of nitrogen during the start-up phase of 30 minutes is followed by a continuous flow rate of $3.5 \mathrm{~m}^{3} / \mathrm{h}$ of nitrogen during the actual production phase. A better isolated process chamber (e.g. vacuum chamber) could reduce the amount of required process gas $\left(\mathrm{N}_{2}\right)$ by more than $70 \%$, which correspondents with a reduction of about $31 \%$ in total environmental impact, for a product with a total production time of 4 hours. For larger products, this reduction will be even higher.

\section{Conclusions}

Based on a systematic methodology for inventorisation and analysis of manufacturing unit processes; significant environmental impact reduction opportunities could be identified. Nevertheless, manufacturing processes are still poorly documented in terms of their ecological performance. The $\mathrm{CO}_{2} \mathrm{PE}$ ! - Initiative (Cooperative Effort on Process Emissions in Manufacturing) has the objective to coordinate international efforts aiming to document and analyze the overall environmental impact for a wide range of available and emerging manufacturing processes, and to generate and provide generic guidelines to improve these impacts. 


\section{Literature}

[1] $\mathrm{CO}_{2} P E$ ! - Initiative (Cooperative Effort on Process Emissions in Manufacturing), http://www.mech.kuleuven.be/co2pe

[2] Gutowski, T., Dahmus, J., Thiriez, A., Electrical Energy Requirements for Manufacturing Processes, In: Proceedings $13^{\text {th }}$ CIRP International Conference on Life Cycle Engineering, Leuven, May $31^{\text {st }}-$ June $2^{\text {nd }} 2006$, pp 623-628

[3] ISO 14001:2004, Environmental management systems - Requirements with guidance for use, International Organization for Standardization

[4] Gutowski, T., Murphy, C., Allen, D., Bauer, D., Bras, B., Piwonka, T., Sheng, $P$., Sutherland, J., Thurston, D., Wolff, E., Environmentally benign manufacturing: Observations from Japan, Europe and the United States, Journal of Cleaner Production, 2005, Vol.13, pp 1-17

[5] ISO 14040:2006, Environmental Management - Life Cycle AssessmentPrinciples and Framework, International Organization for Standardization

[6] ISO 14044:2006, Environmental Management - Life Cycle Assessment Requirements and Guidelines, International Organization for Standardization

[7] ILCD - Handbook, European Commission - Joint Research Centre Life Cycle Thinking and Assessment, Institute for Environment and Sustainability http://lct.jrc.ec.europa.eu/publications

[8] Suh, S., Miet 3.0 User Guide, An Inventory Estimation Tool for Missing Flows using Input-Output Techniques, 2003, CML, Leiden University

[9] Weidema, B., Nielsen,A.M., Christiansen, K., Norris, G., Notten, P., Suh, S., Madsen, J., Priorisation within the Integrated Product Policy, 2005, 2.-0 LCA consultants

[10] Goedkoop, M., SimaPro Database Manual Dutch Input Output Database 95, 2004, PRé Consultants

[11] Environmental Technology Laboratory, LCA Database based on 2000 InputOutput Tables for Japan, 2006, Corporate Research \& Development center, Toshiba Corporation

[12] Global steel life cycle inventory (LCI), 2010, The World Steel Association (worldsteel), http://www.worldsteel.org 
[13] European Aluminium Association, Environmental Profile Report for the European Aluminium Industry, Life Cycle Inventory data for aluminium production and transformation processes in Europe, 2008, http://www.eaa.net/en/environment-health-safety/lca

[14] Eco profiles: life-cycle analysis, PlasticsEurope, Association of plastics Manufacturers, http://www.plasticseurope.org

[15] BUWAL database, Bundesamt für Umwelt, Wald und Landschaft, http://www.bafu.admin.ch

[16] Ecoinvent Centre, Swiss Centre for Life Cycle Inventories, http://www.ecoinvent.org

[17] Steiner, R., Frischknecht, R., 2007, Metals Processing and Compressed Air Supply, Ecoinvent report nr.23.

[18] ELCD database, European Commission - Joint Research Centre, LCA-Tools, Services and Data, http://lca.jrc.ec.europa.eu/lcainfohub/datasetCategories.vm

[19] The Life Cycle Initiative, United Nations Environmental Programme (UNEP) and the Society for Environmental Toxicology and Chemistry (SETAC), http://www.estis.net/sites/lcinit

[20] Wenzel, H., Hauschild, M., Alting, L., Environmental assessment of products, vol. 1: methodology, tools and case studies in product development, 1998, Kluwer, Hingham, MA, USA, p 560

[21] LIME, Life Cycle Impact Assessment Method based on Endpoint Modeling, AIST, http://www. aist-riss.jp/main/modules/groups alca/content0005.html

[22] Jolliet, O., Margni, M., Charles, R., Humbert, S., Payet, J., Rebitzer, G., Rosenbaum R.K., IMPACT 2002+: a new life cycle impact assessment methodology, 2003, International Journal of Life Cycle Assessment 8(6):pp.324-330

[23] Huijbregts, M.A.J., Thissen, U., Guinée, J.B., Jager, T., Kalf, D., van de Meent, D., Ragas A.M.J., Wegener Sleeswijk, A., Reijnders, L., Priority assessment of toxic substances in life cycle assessment. Part I: calculation of toxicity potentials for 181 substances with the nested multi-media fate, exposure and effects model USES-LCA, 2000, Chemosphere 41(4):pp.541573 
[24] Goedkoop M, Müller-Wenk R, Hofstetter P, Spriensma R, The Eco-Indicator 99 explained, 1998, International Journal of Life Cycle Assessment 3(6):pp. 352-360

[25] McKone, T., Bennett, D., Maddalena, R., CalTOX 4.0 Technical support document, 2001 vol 1. LBNL-47254, Lawrence Berkeley National Laboratory, Berkeley, $C A$

[26] MacLeod, M., Woodfine, D.G., Mackay, D., McKone, T.E., Bennett, D.H., Maddalena, R., BETR North America: a regionally segmented multimedia contaminant fate model for North America, 2001, Environmental Science and Pollution Research 8(3):pp.156-163

[27] Bachmann, T.M., Hazardous substances and human health:exposure, impact and external cost assessment at the European scale. Trace metals and other contaminants in the environment, 8, 2006, Elsevier, Amsterdam, p 570

[28] Goedkoop, M., Heijungs, R., Huijbregts, M., De Schryver, A., Struijs, J., van Zelm, R., ReCiPe 2008 - A life cycle impact assessment method which comprises harmonized category indicators at the midpoint and the endpoint level, http://www.lcia-recipe.net/

[29] Rosenbaum, R., Bachmann, T.M., Gold, L.S., Huijbregts, M.A.J., Jolliet, O., Juraske, R., Koehler, A., Larsen, H.F., MacLeod, M., Margni, M., McKone, T.E., Payet, J., Schuhmacher, M., van de Meent, D., Hauschild, M.Z., USEtox - the UNEP-SETAC toxicity model: recommended characterization factors for human toxicity and freshwater ecotoxicity in life cycle impact assessment, 2008, International Journal of Life Cycle Assessment, 13:pp.532-546

[30] GaBi Software, Product Sustainability, PE International, http://www.gabisoftware.com

[31] SimaPro LCA Software, Pré Consultants, http://www.pre.nl/simapro

[32] Umberto - The software for process optimization, http://www.umberto.de

[33] Cluster of Excellence - Energy-efficient Product and Process Innovation in Production Technologies, Chemnitz University of Technology, http://www.eniprod.tu-chemnitz.de/index.php.en

[34] Lind, S., Johansson, B., Stahre, S., Berlin, C., Fasth, Å., Heilala, J., Helin, K., Kiviranta, S., Krassi, B., Montonen, J., Tonteri, H., Vatanen, S. \& Viitaniemi, J, 2009. SIMTER. A Joint Simulation Tool for Production Development. VTT Working Paper 125. 49 p. Espoo. 
[35] Centre for Sustainable Manufacturing and Reuse/Recycling Technologies, http://www.centreforsmart.co.uk/

[36] Solid Works Sustainability, http://www.solidworks.com/sustainability

[37] EPA 2007a, The Lean and Environment Toolkit, U.S. Environmental Protection Agency, http://www.epa.gov/lean/toolkit/index.htm

[38] EPA 2007b, The Lean and Energy Toolkit, U.S. Environmental Protection Agency, http://www.epa.gov/lean/toolkit/LeanEnergyToolkit.pdf

[39] Cash, R., Wilkerson, T., GreenSCOR, Developing a Green Supply Chain Analytical Tool, 2003

[40] Rahimifard, S., Minimisation of Energy Consumption during the Manufacturing Phase of a Product Life Cycle, 2009, Manufacture 2009, Goteborg, Sweden

[41] European Commission, 2009. Energy - Yearly statistics 2007, Luxembourg: Office for Official Publications of the European Communities, ISBN 978-92-7912787-8

[42] Gutowski, T., Dahmus, J., Thiriez, A., "Electrical Energy Requirements for Manufacturing Processes", Proceedings 13th CIRP International Conference on Life Cycle Engineering, 2006, Leuven, pp. 623-628.

[43] Dahmus, J., and T., Gutowski, "An environmental analysis of machining", Proceedings of IMECE 2004, ASME International Mechanical Engineering Congress and R\&D Expo, Anaheim, California USA, November $13^{\text {th }}-19^{\text {th }}$.

[44] CIRP Collaborative Working Group (Energy and Resource Efficiency \& Effectiveness): http://www. cirp-eree.iwf.tu-bs.de

[45] Intelligent Manufacturing System (IMS), Manufacturing Technology Platform (MTP) Theme: $h$ ttp://www.ims.org/content/co2pe-ims-mtp-initiative-2008

[46] DIN 8580, Manufacturing processes - Terms and definitions, division, Deutsches Institüt für Normung e.V., September 2003.

[47] Duflou, J.R., Kellens, K., Devoldere, T., Deprez, W., Dewulf, W., 2010, Energy related environmental impact reduction opportunities in machine design: case study of a laser cutting machine, International Journal of Sustainable Manufacturing, vol:2 issue 1 pp 80-98

[48] Laser Safety database, Laser Zentrum Hannover e.V., http://www.laserzentrum-hannover.de/ 